\title{
Corrosion in Reinforced Concrete
}

\author{
Facundo Almeraya, ${ }^{1}$ José Maria Bastidas, ${ }^{2}$ \\ Andres A. Torres Acosta, ${ }^{3}$ and Citlalli Gaona Tiburcio ${ }^{4}$
}

${ }^{1}$ Advanced Materials Research Center (CIMAV), 31109 Chihuahua, CHIH, Mexico

${ }^{2}$ National Centre for Metallurgical Research (CENIM), CSIC, 28040 Madrid, Spain

${ }^{3}$ Instituto Mexicano del Transporte, 76703 Sanfandila, QRO, Mexico

${ }^{4}$ University Autonomous of Chihuahua, 3100 Chihuahua, CHIH, Mexico

Correspondence should be addressed to Facundo Almeraya, facundo.almeraya@cimav.edu.mx

Received 7 November 2012; Accepted 7 November 2012

Copyright ( 2012 Facundo Almeraya et al. This is an open access article distributed under the Creative Commons Attribution License, which permits unrestricted use, distribution, and reproduction in any medium, provided the original work is properly cited.

Corrosion of reinforcing steel produces important damage to concrete structures in coastal, urban, and industrial zones. This damage has increased in recent years in all countries when concrete is a regular construction material, no matter if it is a technologically advanced country or it is in the process of being one. Reinforcing steel is initially protected by concrete alkaline reserve which helps to maintain the reinforcing steel passive layer. However, chlorides from salty water (i.e., marine water and/or deicing salts) or $\mathrm{CO}_{2} / \mathrm{SO}_{2}$ present in urban/industrial environment accumulate on the concrete surface and then move towards the rebar by known transport mechanisms like diffusion. When the chloride or $\mathrm{CO}_{2}$ threshold is exceeded, depassivation occurs and a corrosion products layer is formed in the rebar perimeter. The volume of this layer is bigger than the original steel consumed; thus, tensile stresses develop and produce concrete cover cracking and spalling. Besides being aesthetics, cracking decreases steel/concrete adherence and, potentially, the structural capacity of the affected structural element. Then, corrosion of reinforcing steel can produce significant damage affecting the whole structural behavior.

Several research groups in the world has been working in the past five decades to determine possible actions to increase the service life of concrete structures, especially the initiation period (time when the aggressive elements such as chlorides and/or $\mathrm{CO}_{2}$ penetrates into the concrete cover until reaching the reinforcing steel and depassivation occurs). This special issue on corrosion of reinforcing steel includes six different papers on this topic: corrosion initiation stage.
Three of the papers deal with the effect of acidic environment on the performance of different concrete mixture types. One of them also includes some interesting nondestructive ultrasonic method to determine the penetration extent of the concrete degradation by the exposure of such acid solutions. Another paper deals with a multiscale method to obtain a relation between porosity characteristics inside the concrete with the damage process of concrete exposed to this acid environment. The third paper deals with the effect of acid exposure to the tensile strength of concrete specimens.

The second topic is directed to a study of an alternative reinforcing steel bar with low alloying nickel content. Results obtained for this low-nickel stainless steel bar in alkaline saturated calcium hydroxide solution showed high corrosion resistance even though chlorides were added to the simulated pore solution or mortar tested as two different electrolytes.

The third topic in this special issue includes the use of natural fibers (sugar bagasse cane and cactus) as potential additions to cement-based materials: sugar bagasse cane was used as a mineral addition to decrease the material porosity, and cactus, as corrosion inhibitor.

Hope this special publication will help the readers to understand particular ways to increase the corrosion initiation stage of reinforced concrete-like materials, and also encourage the possibility to continue research on this field of expertise for the future generations to come.

Facundo Almeraya José Maria Bastidas Andres A. Torres Acosta Citlalli Gaona Tiburcio 

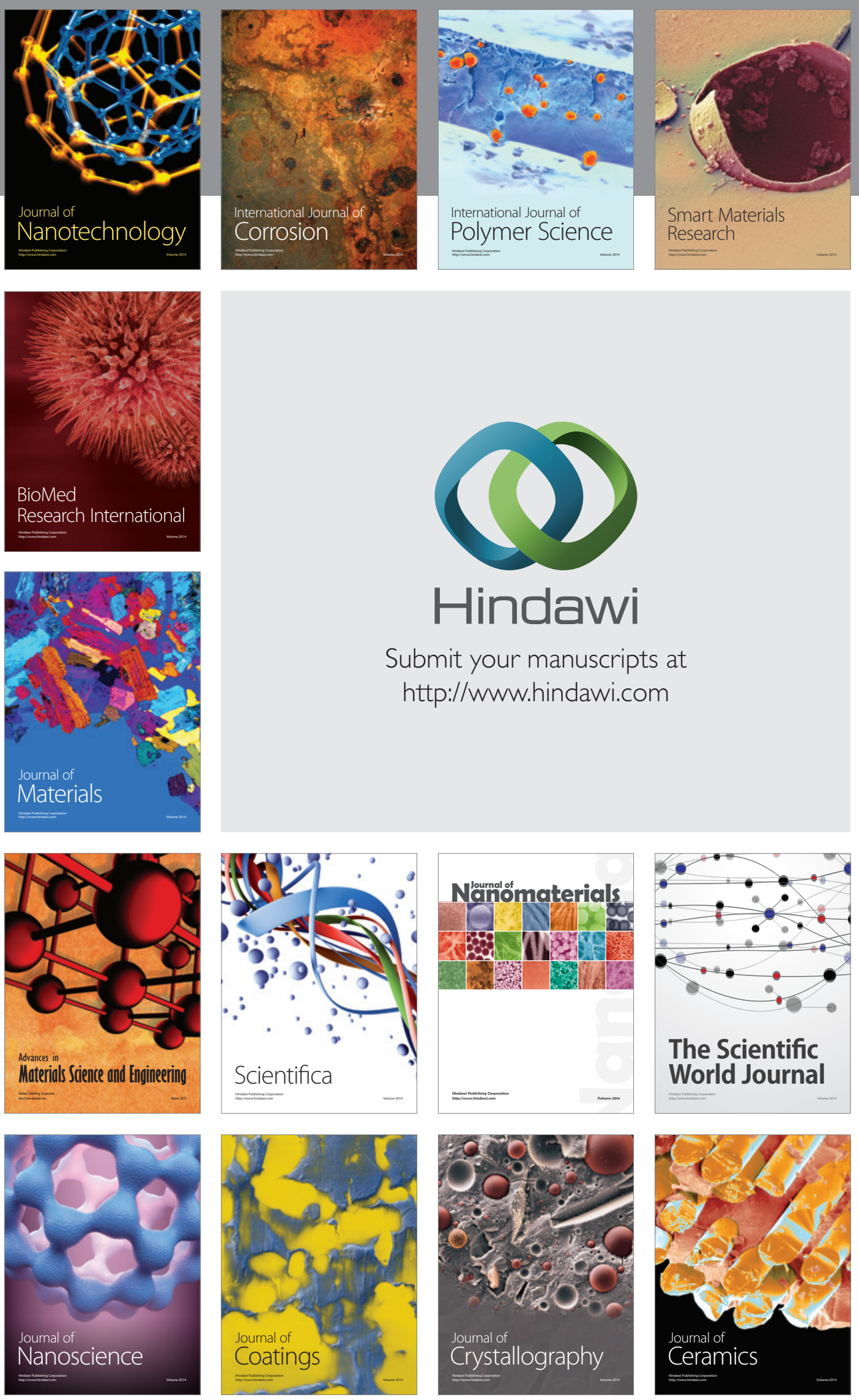

The Scientific World Journal

Submit your manuscripts at

http://www.hindawi.com

\section{World Journal}

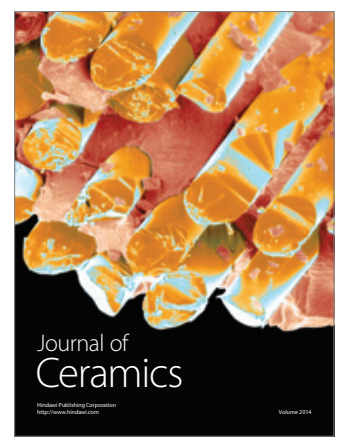

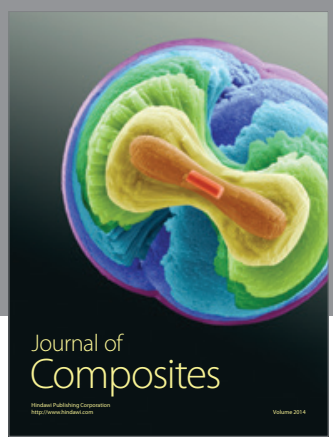
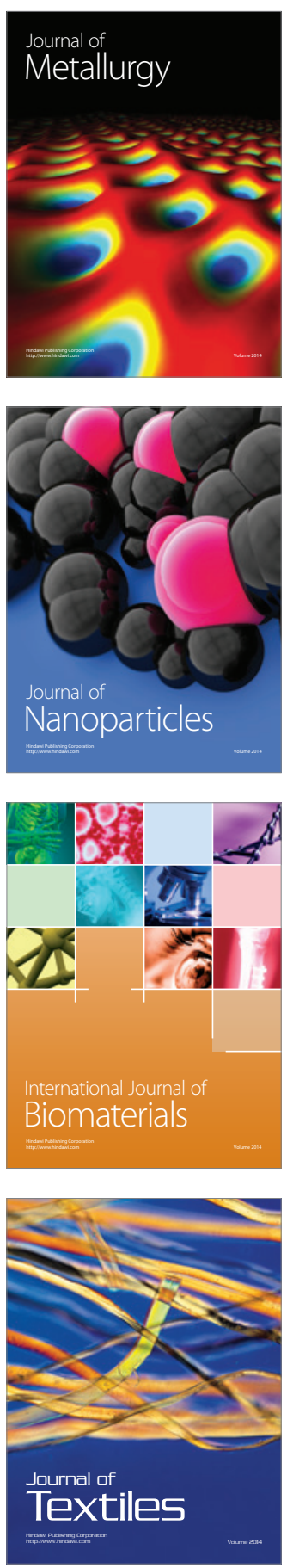